\title{
The party is over: cracking under Sana Distancia in Mexico
}

\author{
Ricardo F. Macip ${ }^{1}$ \\ Published online: 15 July 2020 \\ (C) Springer Nature B.V. 2020
}

Keywords Mexico $\cdot$ Covid-19 pandemic $\cdot$ Political legitimacy

The news regarding the spread and reach of coronavirus or Covid-19 struck early on. By the third week of January, a (ethnically identified Chinese) foreign family toured Mexico City and used Uber, among other means of transportation. The older man in the group was supposedly diagnosed with Covid-19 and was admitted to a hospital upon arrival in Los Angeles, California. After they have left Mexico City, Uber shut down 240 user accounts and put two drivers under observation (DW (Deutsche Welle) n.d., 2ND 2020). The news did not reach much beyond Mexico City and the attitudes towards the contagious disease were mostly ambivalent. Perhaps this story was true, Uber users thought, but if so, it could not be as bad as international broadcasters were depicting it. A few days later, it was no more than another expression of xenophobia identifying Chinese persons as the sources of potential danger (EHDP 1, 30TH 2020).

As the weeks went by, the public who followed the news debated whether the pandemic was real, whether it was capable of reaching Mexico, and if it was real how serious it could be. Very few had the humility to accept the fact that they lack the education, much less the knowledge, to understand what was being talked about. This same scenario happened with authorities at all levels of the government as they became engulfed into the imbroglio. The news during February focused on the city of Wuhan in China and it was treated with exotic sensationalism. By early March, the contagion spread first to other Asian countries and then Mediterranean Europe and North America, which was when the World Health Organization declared it a pandemic (EHDP 3, 11TH 2020), prompting debates involving public figures, business leaders, foreign ambassadors, and academics. These discussions eventually framed the federal government's only consistent approach to the pandemic, known as "Sana Distancia" (healthy distance), abbreviating the nonsensical use of "Jornada Nacional de Sana Distancia" (National Workday of Healthy Distance) as the official title for the policy. This was

Ricardo F. Macip

rfmacip@gmail.com

1 Instituto de Ciencias Sociales y Humanidades, Benemérita Universidad Autónoma de Puebla, Puebla, Mexico 
accompanied by the propagandistic mascot "Susana Distancia" (a cartoon young heroine) meant to help communicate the meaning behind the campaign.

The most relevant aspect of the policy and campaign is that even though there was plenty of reliable and sanctioned information coming from the mismanagement of the emergency in Italy and Spain, in contrast to the tight measures taken in most of Asia, while the cases started to multiply in the United States, governmental officials seemed to compete in ignoring or relativizing the danger in a clownish fashion. True, an undersecretary of the Health Ministry was appointed czar for responding to the pandemic and he started to brief the public in a calm and reassuring manner. However, the gap between what he said and what was done at the federal level created space in which everybody believed whatever they fancied and acted in a most disorganized manner.

This lasted until mid-March, when the two largest mass institutions of superior educationthe private Instituto Tecnologico de Estudios Superiores de Monterrey (ITESM) and the public Universidad Nacional Autónoma de México (UNAM) - decided to suspend "in person" events and move their courses and activities to an on-line environment (EHDP 3, 13TH 2020 $\& 3,17 \mathrm{TH} 2020)$. Pretty soon, research centers, universities, and the superior educational apparatus in general did the same (EHDP 3, 17th 2020), forcing the federal government to react. The response came from the Secretary of Education, who suspended in person schooling for the whole educational sector (K-12 and higher levels). Whether the federal government had plans in place at this point or if their response was caused by the (preemptive) move by universities may be argued. The same if whether the relationship between higher institutions was coordinated or in convergence based on the overwhelming evidence coming from abroad, or how much friction was caused within the whole sector. What appeared as a cascade of announcements by the largest institutions of higher education on the nights of March 11th to 13th (EHDP 3, 31st 2020) prompted a stampede of medium and smaller colleges and universities to which the government responded with the Jornada Nacional de Sana Distancia, i.e., the Sana Distancia campaign. Admittedly, the committed-even if disorganized - opposition to the government has framed it as the drama of civil society versus the State, but I would warn against the reiterated commonplaces (which have been regurgitated ad nauseam to explain everything since the Mexico City earthquake of 1985 onwards, substituting analysis with melodrama). Regardless of the prevalence of the melodrama in academic and popular imagination, what was beginning to unfold offered no redemption in sight. Tragedy may be more an appropriated genre to enliven the events, but we are not in that debate yet (Scott 2004).

Rather than simply caving to the gelatinous and untrustworthy "civil society", the federal government centralized the actions and policies regarding the management of the epidemic. Early on, it sets a monopoly over data gathering, analysis, and truth. Only the federal government could determine what tests where going to be trusted, which institutions have the ability to administer them, and which agencies would process what. On March 23rd Sana Distancia was a structured reality and the "Covid Czar" became the leader of the State's capacity to protect the nation.

In fact, the Sana Distancia campaign consists of three articulated exhortations and their folkloric corollaries. First, everyone is urged to stay home, second to wash their hands repeatedly, and third to avoid touching their face (especially eyes, nose, and mouth). Each entreaty carries its own complications and together built mockery and resistance based on their combined effects. First of all, in order to ask the majority if not all the population to remain home meant they have the possibility to do so. The education sector was the first to demobilize 
its students and labor force designing "work-at-home" schemes. This meant that they negotiated payments and forms of supervision for professors, instructors, and teachers while coordinating the needed electronic resources. This was by far the easiest and at the higher level it barely needed the sanction of the government. Not so on the lower levels (as not all classes have Internet access much less proper devices for learning/studying) but that was promptly settled through simulacra (EHDP 5, 15th 2020). By decree, all things were working properly, no matter everybody knew otherwise. Other services and, above all, productive activities in manufacturing demanded careful arrangements in order to explore if it was possible and, under which conditions, which companies would keep paying the workers which percentages of their salaries. This meant also listing some venues as "essential", whereas others were to halt production. In contrast with this political decision, not devoid of excessive overtones such as the nonessential status of beer and its power to keep the workforce at home or on the streets (EHDP 6, 3RD 2020), services like petty commerce presented several challenges.

Up to 56\% (ENOE- INEGI (Encuesta Nacional de Ocupación y Empleo- Instituto Nacional de Geografía, Estadística e Informática) n.d.) of the economy is informal and there are neither chambers of business, nor unions to negotiate with. There are powerful organizations but they have to be dealt with at a local level. Agriculture, animal husbandry, and fisheries basically regulated themselves according to market demands. With the exception of the vast informal sector, one-by-one businesses in the formal economy pledged to get on board, allowing the possibility to "stay home" to resonate as an echo. Of course, there were problems from the beginning with different groups challenging this and no coercive measures were put in place. Reports of automobile traffic and the tracking of mobile phones indicated that most people were ignoring Sana Distancia and were not staying home.

Those fortunate enough to be able to stay home were asked to wash their hands repeatedly, but in less than a blink, it was clear that this was not a possibility for the majority of the population. Even if the percentage of houses and apartments serviced with running water is as much as $88 \%$ at the national level (with the highest and lowest rates at 99 and 62, respectively for the states of Aguascalientes and Guerrero [INEGI Datos (Instituto Nacional de Goeografía, Estadística e Informática) n.d.), the water supply is not constant. People were asked to choose between following the exhortation or doing the things they usually employ water for. Within this limitation, antibacterial gel surfaced as an alternative to hand washing, but again, it was only for those who could afford it or even knew it existed. Each exhortation immediately presented its own mocking dilemma: the joke was on the classist dummies for not knowing what country they live in and try to rule over. Maybe the easiest recommendation and more difficult to stick to was the avoidance of face touching. The public was informed in amusement of how many times each person usually touches their face during the day and, surprisingly this produced almost no jokes. The three exhortations were marshaled over and over again in TV ads, as official communication in the daily early morning presidential appearances (known as la mañanera) as well as the evening and newly daily presentation of the Covid Czar and his cohort of experts. All in all, this was the only consistent strategy for the pandemic's management.

However, there were three series of shortcomings that undermined Sana Distancia from the beginning. First and most grave among them was the reluctance to test extensively in order to know the extent, distribution, and speed of contagion. Dr. Hugo López Gatell, the aforementioned czar, refused to allow either private institutions or local governments to test or announce their results. Neither he nor any other authority would recognize them. Only his monitoring 
model (Centinela [BBC (British Broadcasting Corporation) n.d., 16TH 2020]) based on public hospital reports from all over the country was to be trusted and he kept a tight control over it during the months that the Sana Distancia campaign lasted. For his commitment towards unregistering cases, by not acknowledging other sources, he was denounced and attacked from the beginning by other trained professionals, media pundits, journalists, and state governors, not to mention everybody who was not persuaded by his reiteration that extensive testing was a waste of money, effort, and attention. The peak of this criticism came in mid May when the correspondent of the Los Angeles Times asked him if the lack of testing was due to lack of funds to which he jokingly answered that that was not the case (ESDM (EL Sol DE MEXICO) n.d., 14TH 2020). In some quarters, to doubt the czar amounted to a declaration of allegiance to the disloyal opposition, while elsewhere people simply recognized that most of us are deeply ignorant about the actual danger and its complexities to really have informed opinions, which was and is true. Yet, the czar's commitment to his monopolistic powers would follow not only him but also the policy itself, making room for generalized distrust. The daily, accumulated, and total numbers of know cases, contagion, and deaths as well as the speed, distribution, and trends were then subjected to skepticism from many quarters. By late April and early May, different estimates were circulating with astronomic figures of geometrical speed for cases, contagion, and death (EHDP 5, 7TH 2020). People who wanted to rely on the czar's authority really did not know if they could, as there was no scientific or technical dialog, just opposing figures.

The second shortcoming of the campaign was the government's inability to reduce the concentration of people and their movements, particularly in the streets and certain areas of the country. Local police followed local ordinances and the National Guard was on hand to help when and where asked for, but in general, the campaign was aimed at persuasion rather than coercion. Whether this was by principle, fear, or weakness of the coercive state apparatus, we would not know. The president stated it was due to his commitment to democratic values (EHDP 4, 28TH 2020); yet like in the other exhortations, most everyone doubted the police and armed forces had the legitimacy to force compliance, given the convulsed history of the last 50 years or so. Last but not least, there was no government aid for businesses or employees, given a draconian decision by the president to avoid any further indebting of public finances even while most countries were providing aid, not only The United States and Canada - references Mexicans are told nowadays not to compare themselves with (EHDP 5, 21sт 2020)_but also countries in Latin America and the "Global South". The only thing the government offered was to enlarge the social programs already in place for poverty amelioration, none of which goes beyond the buying of political loyalties.

So, it was the case that only those who were able to work from home could follow Sana Distancia. Those who were unable to did not have to fear any repression and expected little or nothing in support from the government. As mentioned earlier, among the first to stay home, the most emblematic belonged to the educational sector. In direct contrast, there were informal workers such as street peddlers, who were unable to stay home. If the first also wished to wash their hands and avoid face touching or close contact with others, all the better; the later would go outside and defy authority by misusing face masks and making fun of the lack of public fountains or similar devices with clean running water. This unsettled situation remains to be filled with contentious meanings and interpretations. It was not everybody on their own, but neither a sense of generalized trust. Therefore, the stories and testimonies regarding the days of the Sana Distancia are varied, contradictory, and everything is believable. No simple class correlation would prevail and even though there are recognizable patterns corresponding to 
occupation, income, and education, they are not contained or self-evident truisms accordingly, yet. The main feature of the period (roughly the Spring) was how untenable "Susana Distancia" was as a hero. By the end of May and beginning of June, the cost was calculated in 12 million workers losing their wages (EF (EL FINANCIERO) n.d., 1ST 2020).

The main discernible external force conditioning, demanding specific courses of action and pressuring the Mexican government came from the United States. President Trump was very clear about his desire to avoid disruption and then to restore and synchronize the "chains of supply" within the manufacturing sector in North America. Commonly glossed as "reopening the economy" and with specific goals for specific regions in the US, Mexicans were schooled again on the meaning of "dependency" and/or "integration". Under the shadow of a renegotiated NAFTA (named USMCA by Trump but still known simply as NAFTA 2.0 or NAFTrump), which took most of his administration (2016-2020) to sort out, the restart was scheduled for July 1st 2020; the date was enforced even though cases of Covid-19 continued to rise. What this required was to reclassify as essential all the productive activities that were part of chains of supply and manufacture, so they could resume work by that date. This happened right at the moment when according to international and national official counts, the spread of contagion was at its highest (EHDP 6, 1ST 2020). Exposing to known risk, the working population was simply treated as another fact of life. After all, Mexican nationals have not stopped working in fields all over North America, and neither Canadian, nor Unitedstatesian, much less Mexican governments did other than lip service in press conferences and dispatches. It has to be said that even if the callousness toward Mexican workers has undeniable racial undertones, it is essentially no different to what happened within the US and Canada. The ethnically segmented labor force was pretty much settled long before the current authorities in the three countries took office and Mexicans occupy pretty specific niches within it with wellknown conjugated forms of oppression (Bourgois 1989). In more than one sense, NAFTA worked according to plan.

That going back to work seemed nonsensical to most privileged observers and pundits, filling the web and its outlets with outcries, fed into the hypocrisy of public discourse in Mexico and abroad. Granted, of the three signatories of NAFTA, Canada was the best protecting its citizenry. However, when next year, the guest worker program (Binford 2019) sorts its regiments to be shipped from Mexico (having half of the "market advantage" shared with Central America and the Caribbean) to rural Canada, the numbers and rates of death among those known as "pawns" in Mexico would be less than rosy. More importantly, if the presidential administration of the United States is willing to expose its own population, to expect different treatment towards a population that has been managed as war bounty since 1848 and with official Mexican consent and eagerness since 1942, is disingenuous to say the least. Maybe the majority of the Mexican populations and specifically its working classes did not know what NAFTA had in storage for them when it started in 1994 (Otero 2018), but a whole generation was born and raised to expect little from its reincarnation by 2020 .

Needless to say that there was also internal pressure from Mexican barons of the maquiladora model as well as widespread discontent among the informal sector. They contributed to the presidential decision to "return to the new normality" (EHDP 5, 13тн 2020). That is, to resume activities any way you can (preferably sporting a face mask as a ritualized and empty gesture of compliance). Of course, everybody mocked this rhetoric nonsense from the beginning, pointing that it was more than simple disrespect for the language; it was the capitulation of the federal government to Trump while transferring responsibilities - including for deaths - to local governments. Sana Distancia was over at the federal level, no 
matter what new gimmicks they try (and they blunder with a few like the infamous traffic-light [EHDP 5, 31st 2020]) but states could try to keep it or try their own. State governments would pay the political cost too, which begs the question of whether this was the situation from the beginning.

The case of Puebla seems to sustain this was indeed the case. The state governor, Miguel Barbosa, at first relativized the danger of the pandemic in harmony with the president (LB (LADO B) n.d., 23RD 2020). Later, he pointed out serious shortcomings of specific figures in the president's cabinet mismanaging the pandemic (EHDP 4, 2ND 2020). Eventually, the governor decided to take a course of action on his own (EHDP 5, 18TH 2020). The most significant was to reject June 1ST as the date to resume "essential" activities in mining and construction, but mostly in auto assembly plants. By issuing a decree and lobbying with the executives of Volkswagen and Audi, he was able to postpone the dates to the middle of the month or even later (EHDP 5, 22ND 2020). Whatever the reasons for Audi and Volkswagen, the agreement was perceived as indicating the relative autonomy of the governor from to the president. Of the 32 Mexican states, most have spoken out against the federal response and refused complete compliance to its ordinances, but the significance of Puebla is that the governor belongs to the same party as the president and, because he participated in two elections for the same office in less than a year (2018 and 19), his identification with the president's will was particularly strong.

The friction against governors from different parties makes for media fire-woks without being actually very different from what happened everywhere. What this may mean is that the federal government never had or even tried to exert a hold over the management of the pandemic. If that meant that it did not have enough power over state and local governments is going to be confirmed on the 2021 elections. By June $1^{\text {st }}$, the federal government recognized 10,000 dead by Covid-19. Even though everybody expected the official number to be a conservative count, it reminds to be seen if the Sana Distancia and associated actions are going to become a politically charged boomerang.

The objective to have a clear and unified communication strategy by the federal government unraveled during the first half of June (EHDP 6, 11TH \& 12TH 2020). Starting with the use of a "national traffic light", with four colors (red, orange, yellow, and green), signaling relative degrees of danger/safety and what was possible to do within each of them, which lasted a few hours. State governors rejected the possibility of having only one traffic light, moving first the discussion into complicated negotiations about what would inform each state traffic light, and then into debased attempts by the federation (and allied local governments) into manipulating them. If a "methodology" for such traffic lights was thinkable at the end of May, by the second weekend of June, it was effectively subordinated to political calculations. The contradictions, between what the czar and the president were communicating, reached its highest point by Friday June the $12 \mathrm{TH}$ with the former asking people to stay home and the later to brave into the streets. By the night of Sunday the 14TH, they were unified without counterpointing. The czar gave up and echoed what the president wished. Earlier that day, and in between religious services (Catholic and other Christian denominations), the president reassured the message of his "Decalogue" in search for a spiritually fulfilling life issued a day before. If he was trying to recant himself from his duties concerning the pandemic or was simply mystifying them is not clear. However, starting on Monday the $15 \mathrm{TH}$, all responsibility regarding contagions fell on private citizens. The pressure to handle things locally grew and state governors have to rely on the support they may already had (EHDP 6, 15TH 2020). By 
then, the official death toll have surpassed the mark of 17,500, growing into 20,500 by the end of the week and beginning of summer. The new normality meant maximum exposure at the peak of the pandemic (EHDP 6, 19TH 2020). Rationalizing it is Byzantinism (Gramsci 1971) impure and simple.

The main risk that president López Obrador runs is to get exposed too soon in his term and too intensively against the cracks of his ruling coalition. He presented his election in 2018 as the dawn of a new regime: "The Fourth Transformation of Public Life". Following the standard issue historical periodization in schoolbooks for the basic level (grades 1st to 6th), the popularly known "fourth transformation" (abbreviated as 4T) has been endowed with the transcendence of the previous three (Independence [1810-1921], Reform [1858-1861], and Revolution [1910-1921]). Even if professional historians discredit this presentist vision whenever safe to do so, the fact is that the president is invested in the ability to persuade his base that this is the case. The 4T is supposed to stand in stark contrast to "neoliberalism" and the "neoliberal period" (roughly from 1982 to 2018) and therefore work as a historical block in Gramscian terms: “...i.e., unity between nature and spirit (structure and superstructure)" (Gramsci 1971: 137). Given his popularity success and attempts at establishing the legitimacy of his ruling coalition, the pandemic is most likely to be used by all the opposition as a banner against him.

Precisely because the ruling coalition behind the $4 \mathrm{~T}$ is so odd, in traditional political alliances as a catch-all electoral strategy, and constantly at odds with regard to the potential "social blocks" it claims to mobilize, that no left/right imaginaries in Mexico uphold their historical meanings, its legitimization is a constant work in progress. The president himself is the chief propagandist and chose "the people" and "the poor" as the signifiers to fill with meaning. Even if this is hardly an innovation in Mexico, more so following his party career (Macip 2018) and the use of the people and the poor in "revolutionary" Mexican politics, there is a real danger that the effects of the pandemic will challenge the identification of the president as the champion of an even further impoverished people. The phenotypic racialization of his party and policies aims to legitimize it even before, or without, the need of sophisticated plans. The party, which is considered a movement in the making by its members, is named morena (without capital letters) and stands for "movement for national regeneration" (movimiento de regeneración nacional) but is mostly a metonym for the nation in its religious polysemy. Morena means dark skin in Spanish (coming from the root "Moor"), but in Mexico is a nickname for the Virgin of Guadalupe (see Wolf (1958) and Turner (1974) for basic clarification), the expression of syncretic excess in the Virgin Mary's cult. By threading carefully and in open violation of the "second transformation" (the reform separating the Catholic Church and the State), President López Obrador was unstoppable winning the 2018 election by landslide. In what appeared to be an illustration of "the imaginary networks of political power" (Bartra 2010), morena caught "the nation" in its symbolic net. During the year and a half of his presidency, the president and his project have remained popular. This is what is at stake.

The efforts to characterize Lopez Obrador by his politics by academics and pundits have followed the worldwide fashion of misusing populism as an empty signifier (Laclau 2005). Even if he fits with some of these features (De la Torre 2010), there are enough specifics to consider him beyond that slot. What I find closer to his style and character is what Fernando Coronil (1995) developed for the pre-Chavez Venezuela about the identification of the leader with the nation mediated by the production of magical resources but were based on oil wealth. Regardless of the party and specific class and class-fraction alliances, the illusion of shared wealth coming from the 
subsoil and transformed into magic allowed for the historic block delusion to take hold. However, as Coronil painstakingly illustrated, it was nothing but a series of delirious mirages in elaborated political masquerades. President López Obrador is committed to oil as much as to the transformation of public life under his guidance. It remains to be seen if the consequences of mismanaging the pandemic through a minimalist approach will make a dent or worse. We know there is hardly any future or value in exporting crude oil or refining it at home; we will learn if waving a magic wand and relying on make-belief as a response to the the pandemic will do the trick for most Mexicans.

\section{References}

Bartra, Roger. 2010. Las redes imaginaries del poder politico Pre-Textos. Aldaía.

Binford, Arthur Leigh. 2019. Assessing temporary foreign worker program through the prism of Canada's seasonal agricultural worker program; can they be reformed or should they be eliminated? Dialectical Anthropology 43 (4): 347-366.

Bourgois, P. 1989 Ethnicity at Work Baltimore, The Johns Hopkins University Press.

Coronil, F. (1995) The Magical State The University of Chicago Press, Chicago.

de la Torre C (2010) Populist Seduction in Latin America Ohio University Press, Athens.

Gramsci, Antonio. 1971. Selections from the Prison Notebooks Ed by Quintin Hoare aand Geoffrey Nowell Smith New York. New York: International Publishers.

Laclau, Ernesto. 2005. La razón populista FCE. Buenos: Aires.

Macip, Ricardo F. 2018. AMLO: the big man in Mexico City. Dialectical Anthropology 42 (3): 315-319.

Otero, Gerardo 2018 The Neoliberal Diet University of Texas Press, Austin.

Scott, David. 2004. Conscripts of modernity. Durham: Duke University Press.

Turner, Victor. 1974. Dramas, fields and metaphors. Ithaca: Cornell University Press.

Wolf, Eric. 1958. The Virgin of Guadalupe: Mexican National Symbol. Journal of American Folklore 71: 34-39.

\section{Electronic references}

Access to all of them on June 6th, (2020)

BBC (British Broadcasting Corporation) https://www.bbc.com/mundo/noticias-america-latina-52304983

DW (Deutsche Welle) https:/www.dw.com/es/uber-méxico-en-alerta-por-un-cliente-sospechoso-decoronavirus/a-52229984

EF (El Financiero) https://www.elfinanciero.com.mx/economia/12-millones-de-mexicanos-perdieron-su-salarioen-abril-por-suspension-laboral

ENOE- INEGI (Encuesta Nacional de Ocupación y Empleo- Instituto Nacional de Geografía, Estadística e Informática). https:/www.inegi.org.mx/contenidos/saladeprensa/boletines/2020/enoe ie/enoe_ie2020_02.pdf

ESDM (El Sol de Mexico) https://www.elsoldemexico.com.mx/mexico/sociedad/mexico-aplica-pocas-pruebasde-covid-19-por-decision-tecnica-dice-lopez-gatell-5232194.html

INEGI Datos (Instituto Nacional de Goeografía, Estadística e Informática) https://datos.gob. $\mathrm{mx} /$ busca/dataset/porcentaje-de-poblacion-que-cuenta-con-servicio-de-agua-entubada-en-su-hogar-derechoal-medio-a

LB (Lado B) https://ladobe.com.mx/2020/04/viva-el-mole-de-guajolote-retoricas-de-la-enfermedad/

Publisher's note Springer Nature remains neutral with regard to jurisdictional claims in published maps and institutional affiliations. 